\title{
Modeling dynamics in household car ownership over life courses: a latent class competing risks model
}

\author{
Gaofeng Gu${ }^{1} \cdot$ Tao Feng $^{1}$ (D) . Dujuan Yang ${ }^{2} \cdot$ Harry Timmermans ${ }^{1,3}$
}

Published online: 9 January 2020

(c) The Author(s) 2020

\begin{abstract}
This study presents a latent class competing risks model to examine the influence of sociodemographics and life course events on car transaction behaviour. The types of car transaction and interval times between car transactions events are incorporated in a competing risk model. To capture unobserved behavioural heterogeneity across the population, the model classifies households into different segments. Results estimated based on retrospective survey data show significant heterogeneity exist in household car ownership decisions. The covariates are found to have different effects on car ownership decisions between different classes. Households in the class labelled "Young households without a car" are more sensitive to life course events related to household composition. Households labelled as "middle-aged and aged households with car(s)" are more sensitive to life course events related to job and house locations.
\end{abstract}

Keywords Car ownership · Life events · Latent class competing risks model · Heterogeneity

\section{Introduction}

Car ownership is a key determinant of individual/household activity-travel behaviour. The car gives individuals the opportunity to leave home any time they so desire and provides direct access to any point in space. In other words, car ownership creates more flexibility in

Tao Feng

t.feng@ @ue.nl

Gaofeng Gu

g.gu@tue.nl

Dujuan Yang

d.yang@tue.nl

Harry Timmermans

h.j.p.timmermans@tue.nl

1 Urban Planning Group, Eindhoven University of Technology, Eindhoven, The Netherlands

2 Information Systems, Eindhoven University of Technology, Eindhoven, The Netherlands

3 Department of Air Transportation Management, Nanjing University of Aeronautics and Astronautics, Nanjing, China 
arranging activity-travel needs and alleviates space-time prisms (Rasouli and Timmermans 2014). Therefore, it is important to understand household car ownership decisions.

The current study contributes to the current body of knowledge on car ownership decisions by adopting the a life trajectory perspective. It examines how car ownership and vehicle transactions are influenced by key life cycle events. Previous studies on the relationships between car ownership and socio-demographics, land use, and other life cycle decisions such as residential decision at a particular instance in time, typically ignoring the dynamics, have applied a variety of different models of analysis (e.g. Potoglou and Kanaroglou 2008; Anowar et al. 2014a, b; Guerra 2015; Cao et al. 2019). However, examining car ownership decisions from a dynamic perspective is needed since the level of car ownership evolved over time. Car disposing or purchasing behaviour may partly depend on the increase or decrease of activity-travel needs. Household may purchase or sell a car because their activity-travel needs increase or decrease over time. Thus, the dynamic models have been applied in the studies related to the change of household car ownership. Instead of using the static number of cars as the dependent variable, the dynamic models focus on the change in vehicle size and composition along a time dimension.

Hazard-based models addressing the duration between state changes are particularly suitable for investigating the dynamics of car ownership. However, hazard models cannot account for the types of car transactions including purchasing, replacing and disposing. To overcome the limitation of hazard models, competing risks models, which take the presence of several types of car transactions into account, have been applied to analyse car ownership change (Yamamoto et al. 2004; Yamamoto 2008; Rashidi and Mohammadian 2011). Household life course events have been incorporated as factors influencing holding duration between different car transactions. The household life course events are viewed as triggers of car ownership change, which in previous studies have been treated to equally affect all respondents (of a certain profile). In reality, however, people may react differently to a life course event. Households who have a more conservative lifestyle may be less likely to change their car than others.

To account for the possible heterogeneity, mixture models which incorporate specifically distributed error terms have been used (Bhat and Pulugurta 1998; Yamamoto and Kitamura 2000; Chen and Niemeier 2005). While the mixture models can identify the heterogeneity, it is difficult to choose an appropriate distribution for the error component. In addition, the difference of car ownership decisions among households with different characteristics tends to be ambiguous in mixture models. The distribution of the error component creates difficulties of interpretation and especially application. An alternative model class is the latent class model which considers the relationship between the heterogeneity and socio-demographics.

Therefore, this study is motivated by the idea that blending competing risks and latent class models would be a productive way of accounting for heterogeneity in life events analysis. This is one of the main contributions of this study. The relationship between socio-demographic variables and latent classes in vehicle transactions can be specified more explicitly. The objectives of this study are to (1) improve understanding of the influence of life course events on different types of car transactions decisions; (2) investigate households' heterogeneity by merging the latent class and competing risks model; (3) investigate the relationship between heterogeneous behaviour and sociodemographics to provide a class-level interpretation.

To achieve these goals, this study investigates car transactions decisions using a latent class competing risks model. Different actions related to car transaction decisions including purchasing, replacing and disposing are considered as competing risks. The 
competing risks model incorporates the time elapsed since the previous car transaction to investigate its impacts on the transaction decisions of the current car. Life course events and the attributes of owned vehicles are taken into account as covariates. Further, the latent class competing risks model probabilistically classifies households into different classes and provides a class-level interpretation of the effects of life course events on car transactions. Moreover, a class membership function is specified by incorporating socio-demographical variables.

The paper provides valuable insights into the understanding of household car transactions decision from a life analysis perspective. The impact of life course events and the time elapsed since the previous car transaction are evaluated. The relationship between heterogeneity and socio-demographics are interpreted more clearly in the latent class competing risks model. In addition to analysis, the latent class competing risks model can also be used to provide more accurate predictions of household car ownership from long-term perspectives. The model can be used for example in dynamic agent-based simulations to predict the change of population and car ownership over time. Moreover, it also provides a reference about the household car transactions for policy makers. Policies for the specific class that is active in car purchasing or replacement are considered more effective in the process of encouraging environment-friendly vehicle transactions.

The remainder of this paper is organized as follows. In the next section, we discuss the competing risks model in the context of transportation research. Then, we present the proposed latent class competing risks model and its specifications applied to the car ownership decision. After that, the data collected through a retrospective survey is described, followed by a discussion of the results of the analysis. Finally, the paper is summarized and concluded.

\section{Literature review}

There is a sizeable literature addressing household car ownership decisions. Previous studies on car ownership (see e.g., de Jong et al. 2004; Anowar et al. 2014a; Clark 2007) can be divided into static and dynamic models according to whether the model addresses the change of car ownership or not. Static models focus on the impact of variables on car ownership at a particular time instance, while dynamic models investigate the dynamics of vehicle evolution. Studies related to car ownership were also divided to exogenous models and endogenous models according to whether the car ownership decision treated as independent of other decisions. The exogenous models consider the car ownership decision to be independent of other decisions such as mode choice. The endogenous models jointly analyze vehicle ownership and other choices. This study focuses on the influence of life events on changes in car ownership. To provide the context of this study, we will focus on the studies related to the influence of life course events on changes in car ownership and dynamic models.

\section{Car transactions models considering impact of life-course events}

The number of studies examining the influence of life course events on car possession and change is relatively small. Many more studies in transportation research have analysed household car ownership as a function of socio-demographic variables such as occupation 
and household size in a cross-sectional manner. Potoglou and Kanaroglou (2008) examined the influence of family structure, socio-economic characteristics, and accessibility at the place of residence on car ownership using the MNL model. Oakil et al. (2016) applied logistic regression analysis to explore the effects of urbanization level, household composition, income, and employment on car ownership. In addition to the socio-economic characteristics, the built environment have been found to influence on car ownership. Guo (2013) investigated the impact of residential parking supply on private car ownership using the logit model. This study pointed out that parking supply significantly influences household car ownership decisions. When on-street parking becomes more available, a household tends to own more cars. Huang et al. (2017) investigated the effects of the metro transit surrounding residential on car ownership using cross-sectional data. Results show that metro is negatively associated with car ownership. Ding et al. (2018) found that built environment related variables have significant impacts on car ownership using an integrated multinomial logit and structural equation model. They showed that people living in areas with smaller block size and higher residential and employment densities are more likely to own a car.

Relative to the abundance of cross-sectional studies, the analysis of the effects of child-birth is considerably more modest. Life event may change the travel needs of household and therefore may trigger households to purchase a car. For example, the birth of a child may increase the need for a (second) car in the household. Verhoeven et al. (2005) were the first to apply Bayesian networks to examine the influence of life events on car ownership decisions. Beige and Axhausen (2012) found that moving out of the parents' house leads to changes in car ownership. The probability of changes in car availability increases, when a new person is born in the household. Oakil et al. (2014) investigated change in household car ownership in response to other life events. Using a logistic regression model, Clark et al. (2016) analysed the impact of job change, baby birth, and marriage on the change in household car ownership. The estimation found that childbirth and job change are associated with an increasing number of cars. Adopting a more complicated and flexible model, Wang et al. (2018) found further evidence of this relationship. The results showed that the increase in household size, change in workplace/study location, and residential relocation trigger car acquisition.

\section{Dynamic car transactions models considering unobserved heterogeneity}

In the models related to the dynamics of car ownership which consider the household car transactions over time (Chen and Niemeier 2005; Yamamoto 2008; Rashidi et al. 2011; Oakil et al. 2014, 2018), hazard models have been predominantly used. For example, Jong (1996) applied a hazard model focusing on the replacing of cars, modelling the time elapsed between two vehicle transactions. In addition, different baseline hazard distributions such as the exponential and Weibull distribution were compared. These models allow estimating interval times between successive events, but the type of car transaction is not considered because hazard models can only deal with the situation that duration exit concerns a single event.

To overcome this limitation, competing risks models may be applied. These models are capable of representing both the timing and the type of transaction simultaneously. In travel behaviour research, the application of competing risks models is rare. Leszczyc 
and Timmermans (2002) compared different competing risks models accounting for different conditions to predict the timing and duration of shopping activities. Auld et al. (2012) applied the model to predict activity generation. In the context of car ownership, Yamamoto et al. (2004) are one of the few researchers who applied a competing risks model to analyse actual and intended holding duration of a car. In their model, replacing, disposing, and purchasing were considered as the different event types. Mohammadian and Rashidi (2007) estimated a competing risks hazard model that considered the influence of socio-demographics and life course events.

In addition to the types of car ownership events, the problem of heterogeneity is another issue of concern in hazard modelling. To accommodate the heterogeneity which cannot be explained by covariates, researchers have included a random term to the hazard model (Baizán et al. 2003; Oakil et al. 2014) or estimated latent classes (Van Den Berg et al. 2012; Paleti et al. 2017). Bhat (1996) provided a unified methodological framework to estimate a proportional hazard duration model with a non-parametric baseline hazard distribution and a non-parametric unobserved heterogeneity distribution. Han and Hausman (1990) accounted for heterogeneity by adding a random term to the hazard model in their flexible parametric proportional hazards model. Most of these models performed better than the standard hazard model. However, the method of incorporating a random effect is difficult to interpret and is over-dependent on the assumed distribution of the random term. In addition, the distribution cannot reveal the source of the heterogeneity, which could be used in the prediction or simulation of the dynamic car ownership process.

As to the competing risks models, many researchers introduced heterogeneity by including a random component which follows a specific distribution (Yamamoto et al. 2004; Mohammadian and Rashidi 2007; Yamamoto 2008; Anastasopoulos et al. 2012; Hasan et al. 2013). However, usually the random term is identically distributed and independent of the observed covariates. Two issues deserve further research. First, these models cannot capture the relationship between unobserved heterogeneity in the reaction to life course events and the observed socio-demographics. Such information may be useful to simulate or predict people's car ownership decision. Second, the results obtained from the random effect approach tend to be very sensitive to the choice of the mixture distribution (Heckman et al. 1984). A questionable assumption about the distribution of the random effect will lead to bias.

The latent class model, which assumes a discrete distribution of heterogeneity across classes, could specify the relationship between socio-demographic variables and latent classes. Moreover, it is easier to interpret. Latent class models assume the distribution of heterogeneity takes the form of discrete clusters. Bhat et al. (2004) extended the hazard-based formulation by including a latent segmentation scheme to classify individuals into regular and erratic. Lee and Timmermans (2007) developed a latent class accelerated hazard model for activity episode durations. In this model, the end of the activity is the only type of exit event. Kim et al. (2017) estimated a latent class hazard duration model to analyse different charging behaviour and classified the electric vehicle users into regular and random users by treating charging regularity as a latent variable. These studies proposed latent class models for common survival analysis with one exit event type. The latent class idea has been rarely applied to extend the competing risks model. 


\section{Latent class competing risks model}

In this section, the latent class competing risks model is explained in detail. We first briefly review the theoretical basis of the competing risks model. The features and limitations of this model are discussed. Then, approaches to capture unobserved heterogeneity are presented. Finally, the model development is described.

\section{Competing risks model}

Competing risks occur when more than one type of exit event is possible. In car ownership decisions, competing risks are present because the purchasing, replacing and disposing of a car could be the endpoint of car ownership duration. When the primary outcome is purchasing a car, replacing and disposing a car serve as the competing events.

There are two conventional methods to assess the effects of covariates when competing risks are present: the cause-specific models and sub-distribution models (Putter et al. 2007). The first approach models the effects of covariates on cause-specific hazard functions and treat other type of risks as censored. The second type of models handles the effect on the cumulative incidence function (CIF) of each risk. Both approaches are valid and the choice of most appropriate approach has been discussed at length. The consensus (Koller et al. 2012; Haller et al. 2012; Wolbers et al. 2014a) is that the sub-distribution hazard model is more appropriate for estimating incidences or prediction in the presence of competing risks. However, the cause-specific hazard model is better than the sub-distribution models when the aim is to investigate the triggers of exit events (Andersen et al. 2012; Wolbers et al. 2014a, b). Because the current paper is concerned with the effect of covariates on different types of car ownership decisions, the cause-specific model is chosen. The types of cause include disposing, replacing, and purchasing a car. The cause of the end of a period is one of the $m$ distinct types indexed by $j \in\{1,2, \ldots, m\}$. The hazard of cause $j$ at time $t$ can be formulated as Eq. (1). Correspondingly, the probability density function can be expressed as Eq. (2).

$$
\begin{gathered}
\lambda_{j}(t)=\lim _{\Delta t \rightarrow 0} \frac{P(t \leq T \leq t+\Delta t, J=j \mid T \geq t)}{\Delta t} \\
f_{j}(t)=\lim _{\Delta t \rightarrow 0} \frac{P(t \leq T \leq t+\Delta t, J=j)}{\Delta t}=\lambda_{j}(t) \cdot S(t)
\end{gathered}
$$

where $\lambda_{r}(t)$ is the hazard, $f_{j}(t)$ is the probability density function. $S(t)$ is the survival function which represents the probability that an individual remains in the state until time $t$. $T$ indicates the time of failure, $J$ indicates the type of cause events.

Define $\Lambda_{j}(t)$ as the cumulative hazard function of cause $j$ at time $t$. Define $S_{j}(t)$ as the survival function of event $j$ at time $t$, which means the probability of state change caused by event $j$ does not happen until time $t$. The survival function of cause $j$ at time $t$ can be formulated as:

$$
S_{j}(t)=e^{-\Lambda_{j}(t)}
$$

As the competing risks are independent with each other, the joint survival function $S$ becomes 


$$
S(t)=\operatorname{Pr}\left\{T_{1} \geq t ; \ldots ; T_{m} \geq t\right\}=\prod_{j=1}^{m} \operatorname{Pr}\left\{T_{j} \geq t\right\}=\prod_{j=1}^{m} S_{j}(t)
$$

The likelihood of a specific type of risk treats all other types of risks as censored. Thus, the competing risks are treated as censored data in the cause-specific models. Imagine a sample with $N$ observations, which are subject to $m$ risks. $d_{i j}$ is the indicator that subject $i$ has exit with cause $j . \mathbf{z}$ is the covariates for subject $i$. The likelihood function $L$ can then be written as:

$$
L(t)=\prod_{i=1}^{N} f_{j}(t \mid \mathbf{z})^{d_{i j}} S(t)^{1-d_{i j}}=\prod_{i=1}^{N} \prod_{j=1}^{m} \lambda_{j}(t \mid \mathbf{z})^{d_{i j}} S_{j}(t)
$$

\section{Latent class competing risks model}

Following the studies discussed previously, life course events may change the decision of car transactions and terminate car holding duration. In this latent class competing risks model, life course event variables, and the attributes of vehicles including engine type and whether a first hand or second-hand vehicle which could increase or decrease the hazard of car transactions, are directly incorporated as the covariates of the competing risks. The life course events considered in the model consist of the change in household composition, house location and occupation. To take into account the possible lag and lead effects, household events happening in 1 year before or after the car ownership change were assumed to affect the hazard of car transaction.

In addition, a number of variables with respect to households' socio-demographics are used to define the class membership. In general, households with different socio-demographics may have different reactions to life course events. The variables that have been incorporated to predict class membership consists of the characteristics of occupation and household composition when a car transaction event happens.

Let $\lambda_{j}^{k}(t)$ represent the cause-specific baseline hazard function of risk $j$, for each subject in class $k$. The integrated baseline hazard function is denoted by $\Lambda_{j}^{k}(t)$. Let $\beta_{r}^{k}$ represent the effect of covariate $\mathbf{z}$ on type of cause $j$, for each subject in class $k$. The hazard function of $j$ occurring at time $t$ for each subject in class $k$, can be formulated as

$$
\lambda_{j}^{k}(t)=\lambda_{j 0}^{k}(t) \exp \left(\boldsymbol{\beta}_{j}^{k} \mathbf{z}\right)
$$

Then, the conditional likelihood given that individual $i$ with covariates vector $\mathbf{z}$ belongs to latent class $k$ for the events $j$ has the following form:

$$
L_{i \mid k}=\lambda_{j 0}^{k}(t) e^{\boldsymbol{\beta}_{j}^{\mathbf{k}} \mathbf{z}-\sum_{j^{\prime}=1}^{m} \exp \left(\boldsymbol{\beta}_{j^{\prime}}^{\mathbf{k}} \mathbf{z}\right) \Lambda_{j^{\prime}}^{k}(t)}
$$

The specification of the competing risks model requires a decision regarding the form of the density function. In modelling car ownership duration, existing work (Yamamoto et al. 2004) has shown that the Weibull distribution is the best when compared with other common distributions for the baseline hazard functions of car transactions. In the current paper, the exponential distribution and the Weibull distribution are tested as the baseline hazard to get the best-fit model. The hazard of event $j, \lambda_{r}^{k}(t)$, happened to the household that belongs 
to segment $k$ without considering other covariates can be written as (in case of a Weibull baseline function)

$$
\lambda_{j 0}^{k}(t)=\alpha_{j}^{k}(t)^{\gamma_{j}^{k}-1}
$$

and (in case of an exponential baseline function),

$$
\lambda_{j 0}^{k}(t)=\alpha_{j}^{k}
$$

$K$ represents the number of segmentations in all observations. $\alpha_{j}^{k}$ is the size parameter and $\gamma_{j}^{k}$ is the shape parameter of the Weibull distribution in the baseline hazard function for event $j$ happened to the household that belongs to class $k$. The exponential baseline function in Eq. (8) is the special case of the Weibull baseline function when $\gamma_{j}^{k}=1$.

Conventionally, the probability $w_{k}$ is conditional on the covariates of households. A household $i$, given a set of socio-demographic variables $\mathbf{u}_{i}$, is assumed to have a probability $w_{i k}\left(\mathbf{u}_{i}\right)$ that belongs to class $k$. The $\boldsymbol{\theta}_{k}$ refers to the parameters of the socio-demographic variables. An intercept is included in the $\boldsymbol{\theta}_{k}$. In our study, we represent the class membership using a logit-form function of socio-demographic variables. The probability that a household belongs to class $k, w_{k}$, can be presented by

$$
w_{i k}=\frac{\exp \left(\boldsymbol{\theta}_{k} \mathbf{u}_{i}\right)}{\sum_{k^{\prime}=1}^{K} \exp \left(\boldsymbol{\theta}_{k^{\prime}} \mathbf{u}_{i}\right)}
$$

Given Eqs. (7) and (10), the likelihood function for individual $i, L_{i}$ is given by

$$
L_{i}=\sum_{k=1}^{K} w_{k} L_{i \mid k}
$$

As a consequence, the log-likelihood function of the latent class model is

$$
L L=\sum_{i=1}^{N} \log \left(\sum_{k^{\prime}=1}^{K} w_{k^{\prime}} \lambda_{j 0}^{k}(t) e^{\boldsymbol{\beta}_{j}^{\mathbf{k}} \mathbf{z}-\sum_{j^{\prime}=1}^{m} \Lambda_{j^{\prime}}^{k}(t)}\right)
$$

To estimate the parameters of each competing risks in each class, the maximum likelihood estimation method is used.

\section{Data}

To investigate the influence of life course events on car ownership decisions, panel data which record changes in car ownership and life events over time are required. A multi-wave panel survey is the most frequently used method to collect panel data. Data collected using this method is relatively reliable as all events are recorded as long as they happen. However, the time span between life course events covers long time spans, hence, a multi-wave panel survey is expensive and it is difficult if not impossible to track respondents for many years to collect enough information about life course events. A retrospective survey is an alternative method to collect panel data. Retrospective surveys have been developed and applied to analyse the relationship with behaviour and 
Table 1 The information collected from the life trajectory survey

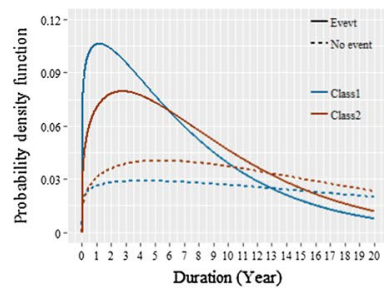

(a1) Baby birth (purchase)

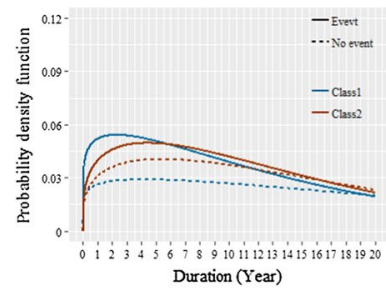

(b1) Marry (purchase)

\begin{tabular}{ll}
\hline Life trajectory & Information \\
\hline Education events & Start time, end time, education type \\
Marital events & Time of marry, divorce, widow (if any) \\
Housing events & Start time, end time, house type, address \\
Occupation events & Start time, end time, job type \\
Car ownership events & $\begin{array}{c}\text { Start time, end time, engine type, new or } \\
\text { second hand }\end{array}$ \\
\hline
\end{tabular}

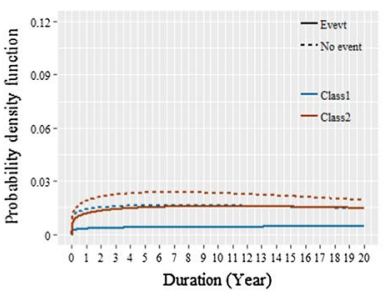

(a2) Baby birth (dispose)

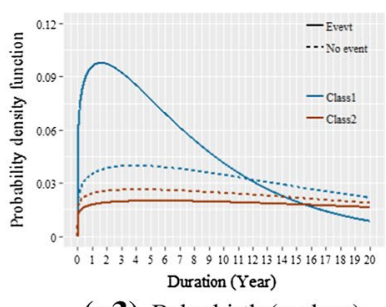

(a3) Baby birth (replace)

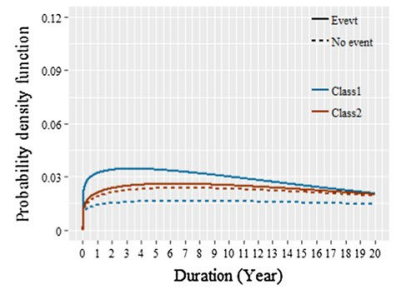

(b2) Marry (dispose)

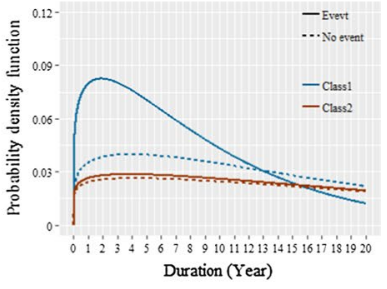

(b3) Marry (replace)

Fig. 1 Example of life trajectory data

life course events for many decades. (Belli 1998; Verhoeven et al. 2005; Beige and Axhausen 2008; Sharmeen et al. 2014); Wang et al. 2018)

In our retrospective survey, respondents were asked to recall their past life course events. The data were collected in the Netherlands in 2017. Households were invited to fill out the details of the life course events they have experienced. For the household composition events, the time of each occurrence of the marital status change in the household was recorded. In addition, information on the birth year of each household member was collected to acquire the baby birth event in the household. For the occupation event, respondents were asked to give the details of each job including the duration, type of job and number of hours. For the car ownership history, the service time of each vehicle, the engine type and whether the vehicle is second-hand were recorded. For the residential event, information about the location and ownership of all the places the respondent had lived was collected. To ensure that respondents have a history of car ownership events, respondents should be at least 24 years old. The information provided for each type of life course event is listed in Table 1.

Figure 1 is an example of the life trajectory of a respondent. Each household event is marked on the timeline. A bold vertical line indicates the car ownership events. The 
circles indicate that an event took place 1 year before or after the car transaction. The number under the line indicates the time by years.

The retrospective survey needs respondents to recall past events. The reliability of the retrospective data depends on respondents' memory recall. The amount of information respondents can recall decreases with the passing of time. However, many studies found that people tend to remember major events such as the increase and decrease of family members, residential relocation, and the change of job. (Hollingworth and Miller 1996; Beige and Axhausen 2012). However, it is still difficult to completely remove the influence of memory.

To reduce the bias caused by recalling the events, respondents were reminded of any inconsistencies when providing information and asked to correct the data provided. Many error-check logics were incorporated in the online survey system. Firstly, respondents were asked their current situation such as education, marital status, car ownership, and occupation. Then, they answered the questions about their life history. The latest life event they reported should be consistent with their current situation. For example, people who mention they have two cars currently should at least report two times of car transactions. People who said they are married currently must report their last marriage event. If they did not report these events, they were prompted to check the data they provided. Secondly, the time of the life event was checked. For example, respondents were asked to check their answer when the end time of a car ownership state is earlier than the start time. As for the relocation events, the start time of a house they live in should be consistent with the end time of the previous house.

Thus, to the extent possible, memory recall bias was minimized during the actual data collection process. In addition, respondents who completed the questionnaire within $10 \mathrm{~min}$ were disregarded in the analysis because it is doubtful they paid sufficient attention to the questions and tasks.

The Web-based survey was implemented through a survey company in the Netherlands. Finally, 1734 respondents completed the questionnaire. Correspondingly, 8114 observations of household car ownership change were available for analysis.

\section{Description of the sample}

Table 2 represents the sample distribution of the current socio-demographics and car ownership. It shows that the different age groups are more or less equally represented in the sample, which is similar to population statistics. The percentage for the group younger than 40 years of age is $26.1 \%$; for the group between 41 and 60 , it is $35.9 \%$; for the group older than 61 years of age, it is $38.1 \%$. Regarding the age of the youngest child, the percentage of households who have a child younger than 6 years old is $11.4 \%$; for the groups between 7 and 12 years old, older than 12 years and no child, the percentages are $7.0 \%, 13.9 \%$, and $67.6 \%$, respectively. In addition, the majority of respondents $(72.0 \%)$ is married or living together with a partner. The frequency distribution of house ownership levels suggests that the majority of respondents $(60.7 \%)$ own a house. As for the number of cars, $11.9 \%$ of the respondents have no car. The percentage of households with 1 car is $60.3 \%$, while households have more than 1 car represent less than one-third of the sample. As for the education, the education levels in Netherlands are categorized into two levels. Primary school, pre-vocational secondary education, general secondary education, and secondary vocational education are classified as low education level. Higher general and preparatory academic education, higher professional education, bachelor and master degree and higher are classified as high education level. The results show 
Table 2 Descriptive statistics of the respondents' sociodemographics $(\mathrm{N}=1734)$

\begin{tabular}{llcl}
\hline Items & Levels & Frequency & Percentage (\%) \\
\hline Age & 24-40 years & 452 & 26.1 \\
& 41-60 years & 622 & 35.9 \\
Age of child & $>60$ & 660 & 38.1 \\
& 0-6 years & 198 & 11.4 \\
& 7-12 years & 122 & 7.0 \\
& $>12$ years & 311 & 17.9 \\
Marital status & No child & 1131 & 63.6 \\
& Single & 486 & 28.0 \\
House ownership & Couple & 1248 & 72.0 \\
& Own & 1052 & 60.7 \\
Occupation & Rent & 682 & 39.3 \\
& Full time job & 1224 & 70.6 \\
Education level & Others & 510 & 29.4 \\
& Low & 907 & 52.3 \\
Number of cars & High & 827 & 47.7 \\
& No car & 207 & 11.9 \\
& 1 & 1045 & 60.3 \\
& 2 or more & 482 & 27.8 \\
\hline
\end{tabular}

that the percentage of people who received a low education $(52.3 \%)$ is slightly greater than the percentage of people who received a high education (47.7\%).

\section{Description of the car transaction observations}

In addition to respondents' current socio-demographics, the car ownership changes that respondents experienced were recorded. The socio-demographics at the time of car ownership change were also recorded. The frequency distributions of the selected socio-demographic characteristics associated with the car transactions observation are listed in Table 3. As shown, the age of the respondents when car ownership changed was categorized into three categories. The majority of observations (53.5\%) were made when respondents were between 24 and 40 years old. The percentages for 41-60 years and older than 61 years of age are respectively $32.8 \%$ and $13.7 \%$.

More than $86 \%$ of the respondents have no children or a child older than 12 years old when a vehicle transaction was observed, while households with a child under 6 years represent $9.3 \%$ of the observations. When buying or selling a car, the percentage couples $(56.4 \%)$ is slightly higher than the percentage singles (43.2\%). Similarly, at that time, $53.3 \%$ owned a house. The frequency distribution of education levels suggests that the majority of the respondents $(53.6 \%)$ did not hold a high education degree when they bought/sold a car. 
Table 3 Socio-demographics and distributions of observations $(\mathrm{N}=8114)$

\begin{tabular}{llcc}
\hline Items & Levels & Frequency & Percentage (\%) \\
\hline Age & $24-40$ years & 4339 & 53.5 \\
& $41-60$ years & 2660 & 32.8 \\
Age of child & $>60$ & 1115 & 13.7 \\
& $0-6$ years & 758 & 9.3 \\
& $7-12$ years & 334 & 4.1 \\
Marital status & N12 years & 7022 & 86.5 \\
& No child & & \\
House ownership & Single & 3537 & 43.6 \\
& Couple & 4577 & 56.4 \\
Occupation & Own & 4326 & 53.3 \\
\multirow{3}{*}{ Education level } & Rent & 3788 & 46.7 \\
\multirow{2}{*}{ Number of cars } & Full time job & 6711 & 82.7 \\
& Others & 1403 & 17.3 \\
Car type & Low & 4349 & 53.6 \\
& High & 3765 & 46.4 \\
Engine type & No car & 1798 & 22.2 \\
& 1 & 5794 & 71.4 \\
& 2 or more & 522 & 6.4 \\
& New & 3402 & 41.9 \\
& Used & 4712 & 58.1 \\
& Electric vehicle & 316 & 13.9 \\
& Conventional vehicle & 7798 & 96.1 \\
\hline
\end{tabular}

\section{Results}

A number of covariates was incorporated in the latent class model. Table 4 presents the definitions of the covariates used in the model. The covariates related to household composition consist of baby birth and marriage. Note that the marriage here means gaining

Table 4 Explanation of the covariates

\begin{tabular}{ll}
\hline Baby birth & $\begin{array}{l}1 \text { If a baby born before or after the change of car ownership in } 1 \text { year, }-1 \\
\text { otherwise }\end{array}$ \\
Marriage & $\begin{array}{r}1 \text { If the respondent married before or after the change of car ownership in } \\
1 \text { year, }-1 \text { otherwise }\end{array}$ \\
Residential relocation & $\begin{array}{l}1 \text { If the respondent moves before or after the change of car ownership in } \\
1 \text { year, }-1 \text { otherwise }\end{array}$ \\
Change of job & $\begin{array}{l}1 \text { If the respondent changes the job before or after the change of car own- } \\
\text { ership in } 1 \text { year, }-1 \text { otherwise }\end{array}$ \\
Ownership of electric vehicle & $\begin{array}{l}1 \text { If the respondent owns an electric vehicle when change the car owner- } \\
\text { ship state, }-1 \text { otherwise }\end{array}$ \\
Ownership of first-hand vehicle & $\begin{array}{l}1 \text { If the respondent owns a brand-new vehicle when change the car owner- } \\
\text { ship state, }-1 \text { otherwise }\end{array}$
\end{tabular}


partner which is a marriage event but not a marital status. Moving house and change of job were also taken into account. The vehicle attributes consist of the type of vehicle and whether it is a used car. For the class membership probabilities, the age of respondents, the age of the youngest child, education level, occupation, house ownership, and the number of cars were included. Similar to the life course events, effect coding was used to represent the various attribute levels of these variables.

To determine the optimal number of classes and baseline hazard functions, models with various numbers of classes and different baseline distributions were estimated using the maximum likelihood estimation method. The $\mathrm{R}$ software was used to estimate the model. Results of BIC and AIC values of different models are listed in Table 5.

Results based on different distributions indicate that the model with the Weibull baseline hazard function provides the best fit. The comparison also shows that the AIC and BIC statistics decrease if the number of classes increases from 1 to 2 . When the number of classes is more than 2, the AIC and BIC start to increase, which means the Weibull baseline hazard function and 2-class model have the best performance. Moreover, the probability that an observation belongs to a particular class can be calculated using the membership function. For the model with the Weibull baseline and 2 classes, 38.9\% of the observations were allocated to class $1,61.1 \%$ of the observations were allocated to class 2 . For the model with the Weibull baseline and 3 classes, $43.9 \%$ of the observations were allocated to class $1,50.2 \%$ of the observations were allocated to class 2 , and only $5.9 \%$ of the observations are allocated in class 3 . The proportion in class 3 is too small and it needs to be omitted. According to the analyses above, a competing risks model with 2 classes and a Weibull distribution is identified as the best model and considered in further analyses.

Table 6 shows the estimation results. To explore the performance of the latent class competing risks model, we compared the results with that of a standard competing risks model. In a standard competing risks model, the covariates are assumed to have constant effects on specific risks across the population. The results of the standard competing risks model show that most covariates have a significant influence on the hazard of car ownership change at the $95 \%$ confidence level. Baby birth, marriage, relocation, and change of job increase the probability to purchase a car or replace a car. When the respondent experiences any of above life course events, the probability of purchasing or replacing car increases.

For the effect of a specific life course event, the standard competing risks seem ambiguous. For instance, marriage triggers a change in car ownership, perhaps purchasing, but also possibly disposing or replacing. The homogeneity assumption without considering the

Table 5 The comparison of models with different number of latent classes and baseline function

\begin{tabular}{lllccc}
\hline Baseline hazard & Classes & Log likelihood & Parameters & AIC & BIC \\
\hline Weibull & 1 & $-28,116.4$ & 24 & $56,280.7$ & $56,448.8$ \\
& 2 & $-23,368.7$ & 60 & $46,857.4$ & $47,277.5$ \\
& 3 & $-23,419.2$ & 96 & $47,030.5$ & $47,702.6$ \\
Exponential & 4 & $-23,459.5$ & 132 & $47,183.04$ & $48,107.22$ \\
& 1 & $-27,149.3$ & 21 & $54,340.54$ & $54,487.57$ \\
& 2 & $-23,516.4$ & 54 & $47,140.78$ & $47,518.85$ \\
& 3 & $-23,492.5$ & 87 & $47,159.06$ & $47,768.18$ \\
& 4 & $-23,477.2$ & 120 & $47,194.32$ & $48,034.48$ \\
\hline
\end{tabular}




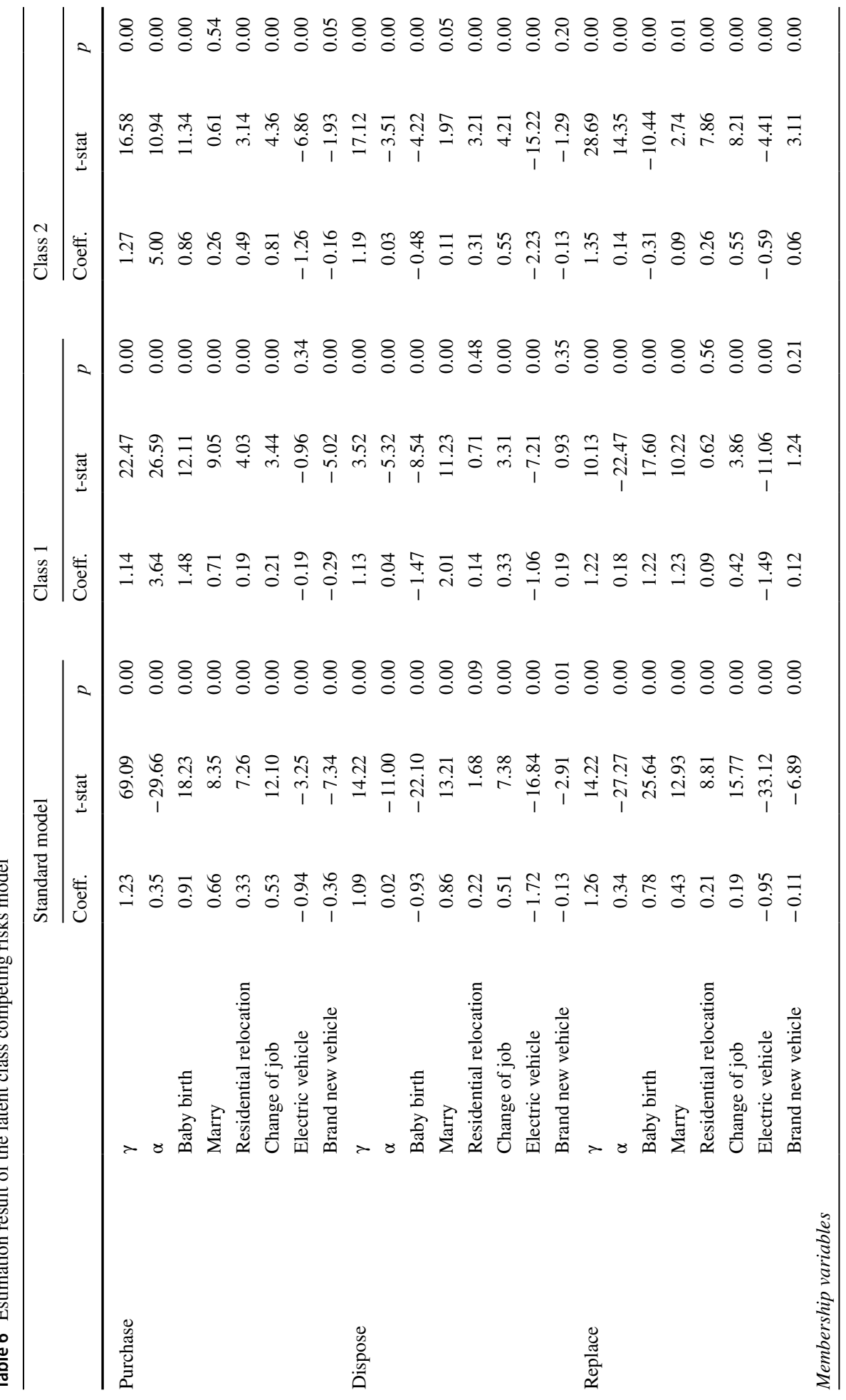




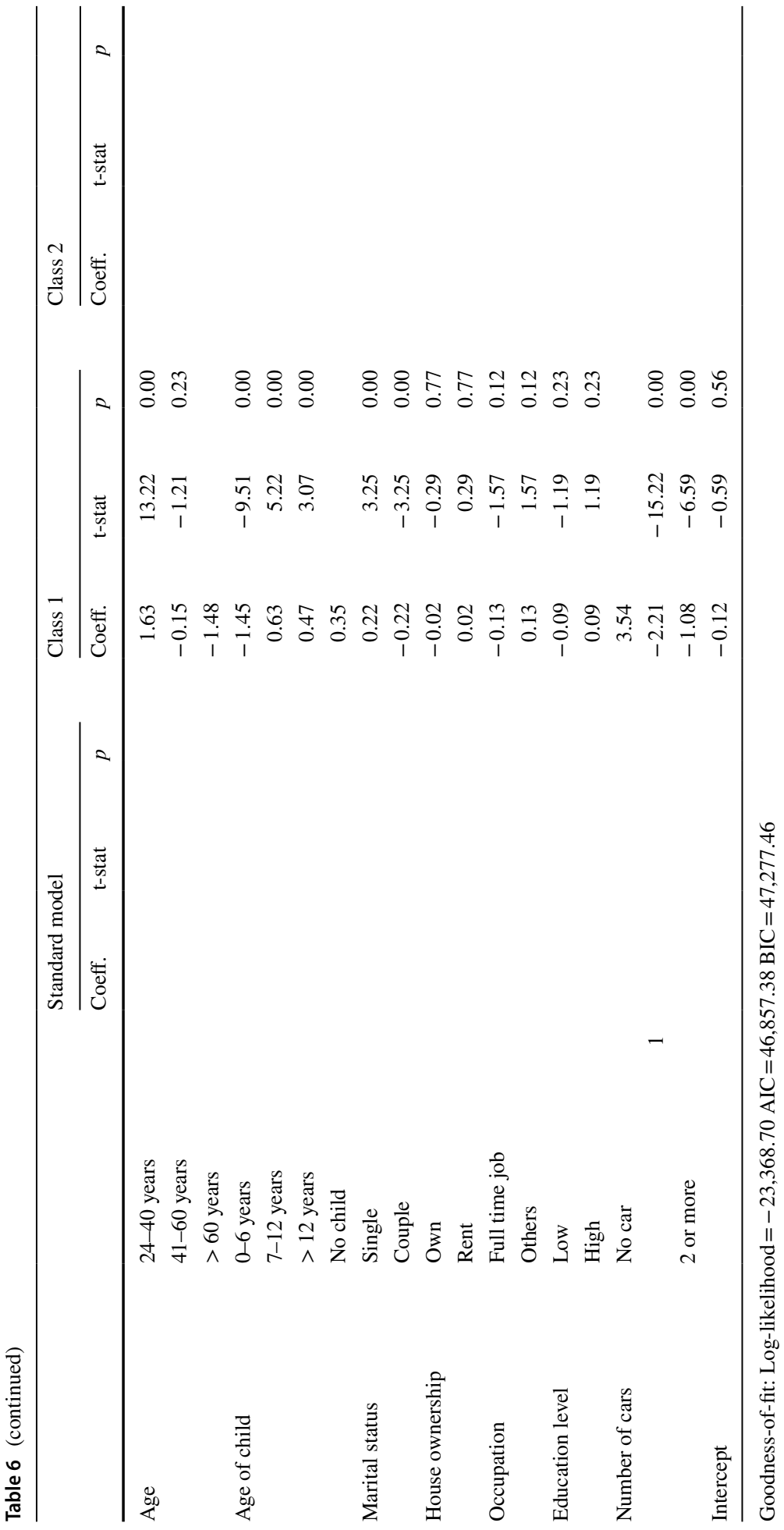


socio-demographics makes it difficult to model the influence of covariates on car ownership decisions. The standard competing risks models seem to ignore the significant unobserved heterogeneity. The results of the latent class model confirm the clear difference between the two classes, which means heterogeneity exists among individuals.

The parameters of the variables used to explain the membership of the latent classes are listed in Table 6. The results indicate that most variables have a significant effect on membership probabilities at the $95 \%$ confidence level. There are two latent classes in this model and the second latent class is treated as the reference. Positive values of membership variables for latent class 1 mean negative values for latent class 2 . The parameter of age younger than 40 years old is positive, indicating that young people are more likely to belong to latent class 1 . Latent class 2 is more likely to consist of people older than 40 . The parameter for age of the child who are younger than 6 years old is relatively large and negative, implying that households with a child younger than 6 years have a higher probability to belong to class 2 . The parameter for marriage takes on a negative sign, which means that married people are less likely to belong to class 1 . The parameter of no car is positive, which means that people without a car have a higher probability to belong to class 1 than to class 2. Generally, the parameters of age and number of cars in households are relatively large, which reveals that class 1 could be labelled as "young households without a car" and class 2 could be labelled as "middle-aged and aged people with car(s)". The impact of life course events on each type of car transaction are presented in Fig. 2.

\section{Car purchasing behaviour}

According to the estimated parameters, households in each class are most sensitive to baby birth when purchasing a car. The positive parameters of baby birth for the two classes mean that people are more likely to purchase a car when a baby is born. It suggests that baby birth generates a shift in travel demand such as escorting the child to a day care centre

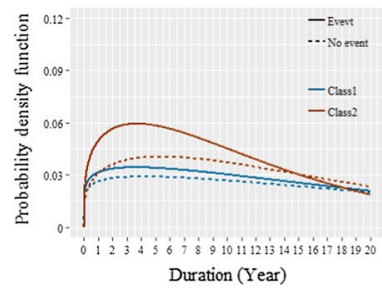

(c1) Residential relocation (purchase)

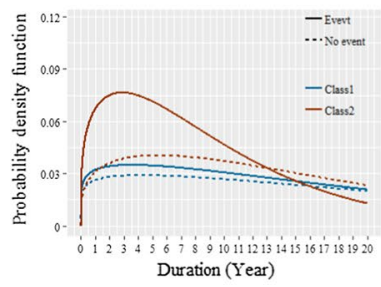

(d1) Change of job (purchase)

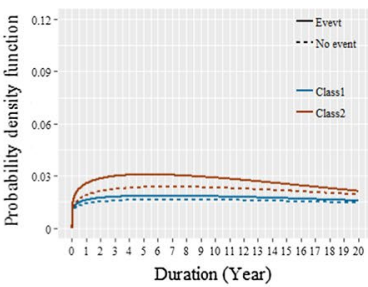

(c2) Residential relocation (dispose)

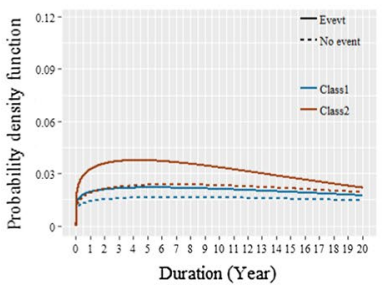

(d1) Change of job (dispose)

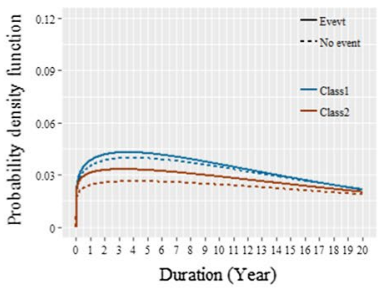

(c3) Residential relocation (replace)

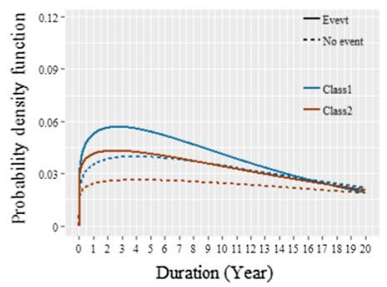

(d3) Change of job (replace)

Fig. 2 The impact of life course events on the probability density functions of car transactions 
and other locations. In addition, the comfort and convenience of a car are important when a baby is present in the household. This is in line with the findings from previous studies (Oakil et al. 2014; Clark et al. 2016). The parameter of getting married is significant for class 1 but not for class 2, indicating that households in class 1 have a higher probability to purchase a car than those in class 2 when they get married. For the change of house location, the effects are similar for the households in different classes in the sense that car ownership increases when they move, indicating that people prefer to purchase a car when they move. The parameters for change of job in the two classes are both positive, which means that people prefer to purchase a car when they change their job. For car attributes, once the households own an electric car, they have a lower probability to purchase a new car. Owning a brand-new car has a similar effect for both classes. The baseline hazard shows a considerable difference between the baseline hazards of the two classes. The baseline hazard for class 2 is higher than that of class 1 . Class 2 has a higher probability to purchase a car than class 1 without consideration of other covariates.

According to the sensitivity analysis of each types of life events (see Fig. 2, (a1), (b1), (c1), and (d1), the impact of baby birth on car purchasing is greater than that of other events for people in class 1 , while the change of job has the biggest impact for people in class 2 .

Through comparatively analysing the difference between two classes, we found that households are more sensitive to baby birth and marriage in class 1, and to a change of job and house relocation in class 2 . Combined with the characteristics of the two classes, the effects of life course events on car purchasing indicates that young people tend to attach a greater weight to household composition when they decide on car ownership. In addition, households without a car are more likely to belong to class 1, which implies that people purchase the first car mostly because of changing household composition. For a mid-aged and aged household, people attach a higher weight to the change of job and house relocation. A change of job or house relocation implies a different commuting distance and public transport availability. A car purchasing decision seems to be an adaptation to this changing context to improve convenience.

\section{Car disposing behaviour}

Regarding car disposing, baby birth has a negative ( -1.47 for class 1 and -0.48 for class 2) and significant effect on the probability of selling a car. In contrast to the parameter of the baby birth event, parameters of marriage, residential relocation, and change of job are all positive, which indicates that people have a higher probability to sell a car when these events happen. Specifically, for people in class 1, the probability of selling a car increases when they get married. For people in class 2, marriage has no significant influence on the decision to sell a car. Moving house increases the probability to sell a car for people belonging to class 2, while it does not have a significant effect on the people belonging to class 1 . The probability of selling a car increases when people change job, regardless of which class a household belongs to. For the attributes of a car, when people own an electric vehicle, they are less likely to sell a car. In addition, whether their current car is a brand-new car has no significant influence on car selling decisions. Households in class 2 are more likely to sell their car as the $\gamma$ of baseline hazard is higher than for households in class 1 . In general, the difference between the two latent classes in selling a car is similar to the purchasing a car. 
According to the sensitivity analysis of each types of life events (see Fig. 2, (a2), (b2), (c2), and (d2)), the probability of car disposal decreases sharply in the case of baby birth for people in class 1 , while the probability of car disposal increases most obviously in the case of job change for people in class 2 . Households in class 1 are more sensitive to changes in household composition while households in class 2 are more sensitive to changes in house location.

\section{Car replacing behaviour}

In the case of car replacement, households in class 1 are more likely to replace a car while people in class 2 are less likely to replace a car. People who get married are more likely to replace a car in both classes. Residential relocation has a significant influence on the decision of replacing a car for people belonging to class 2 , while it has no significant influence for people belonging to class 2. Change of job will trigger replacing a car for both classes. Similar to the previous two types of car ownership change, households in class 1 are more sensitive to marriage and baby birth than house relocation and change of job. In contrast, households in class 2 are more sensitive to change of job and house location. The baseline hazard is higher for class 2 than class 1, indicating that households in class 2 are more likely to replace their car.

\section{Conclusions and discussion}

This paper proposed a latent class competing risks model to analyse long-term car ownership decisions considering the effects of life course events. To solve the unobserved heterogeneity problem, households were classified into different latent segments by incorporating a membership function. The model identified different classes and estimated the effects of life course events on car ownership decision for each class separately. The effects of covariates on each class and each type of car transaction were captured. Using life trajectory data collected in the Netherlands, parameters of the baseline hazard and covariates were estimated. The results of the standard competing risks model and the latent class competing risks model were compared. We found that there is a substantial amount of heterogeneity across the population. The latent class competing risks model offers a better insight into the relationships between car ownership decisions and life course events.

The comparison between two classes indicates "young households without a car" are sensitive to the change in household composition, while "middle-aged and aged households with car(s)" are sensitive to the change in job or residential location. The life events leading to the first car in households are different from those leading to the second or third car.

Moreover, for the attributes of car, the electric vehicle has a significant and negative influence on the probability of each type of car transaction, while the variable of brand new car has a significant influence only on car purchasing decision. The proposed latent class competing risks model is potentially valuable to incorporating life course events to the change of car ownership and reveals the relation between unobserved heterogeneity and socio-demographics. The estimated results could be applied in the simulation of long-term car ownership forecasting.

Perhaps the major potential limitation of the present study is that income is not incorporated into the model. In the retrospective survey, many respondents did not provide 
information about their past income. This is perhaps because income information is difficult to recall and respondents may be reluctant to provide income information. In addition, the details of the past built and social environments such as distance to a bus stop are difficult to collect due to limitations in respondents' memory recall, particularly if they did not use the bus. Thus, future research may consider using multi-wave panel data to include more life course events and socio-demographic variables as covariates into the analysis of car ownership decisions.

Acknowledgements This study was supported by research project DESENT (Smart Decision Support System for Urban Energy and Transportation, 2016-2019), funded by JPI Urban Europe (Grant No. 5637396), under the scheme of ERA-NET Cofund Smart Cities and Communities joint research program (ENSCC). The ENSCC call was the product of a joint effort with the Smart Cities Member States Initiative.

Open Access This article is licensed under a Creative Commons Attribution 4.0 International License, which permits use, sharing, adaptation, distribution and reproduction in any medium or format, as long as you give appropriate credit to the original author(s) and the source, provide a link to the Creative Commons licence, and indicate if changes were made. The images or other third party material in this article are included in the article's Creative Commons licence, unless indicated otherwise in a credit line to the material. If material is not included in the article's Creative Commons licence and your intended use is not permitted by statutory regulation or exceeds the permitted use, you will need to obtain permission directly from the copyright holder. To view a copy of this licence, visit http://creativecommons.org/licenses/by/4.0/.

\section{References}

Anastasopoulos, P.C., Haddock, J.E., Karlaftis, M.G., Mannering, F.L.: Analysis of urban travel times: hazard-based approach to random parameters. Transp. Res. Rec. J. Transp. Res. Board 2302, 121-129 (2012)

Andersen, P.K., Geskus, R.B., De Witte, T., Putter, H.: Competing risks in epidemiology: possibilities and pitfalls. Int. J. Epidemiol. 41, 861-870 (2012)

Anowar, S., Eluru, N., Miranda-moreno, L.F.: Transport reviews : a transnational alternative modeling approaches used for examining automobile ownership: a comprehensive review. Transp. Rev. 34, 441473 (2014a). https://doi.org/10.1080/01441647.2014.915440

Anowar, S., Yasmin, S., Eluru, N., Miranda-Moreno, L.F.: Analyzing car ownership in Quebec City: a comparison of traditional and latent class ordered and unordered models. Transportation (Amst) 41, 10131039 (2014b). https://doi.org/10.1007/s11116-014-9522-9

Auld, J., Rashidi, T.H., Javanmardi, M., Mohammadian, A.: Dynamic activity generation model using competing hazard formulation. Transp. Res. Rec. J. Transp. Res. Board 2254, 28-35 (2012)

Baizán, P., Aassve, A., Billari, F.C.: Cohabitation, marriage, and first birth: the interrelationship of family formation events in Spain. Eur. J. Popul. 19, 147-169 (2003)

Beige, S., Axhausen, K.W.: Long-term and mid-term mobility decisions during the life course: experiences with a retrospective survey. IATSS Res. 32, 16-33 (2008)

Beige, S., Axhausen, K.W.: Interdependencies between turning points in life and long-term mobility decisions. Transportation (Amst). 39, 857-872 (2012). https://doi.org/10.1007/s11116-012-9404-y

Belli, R.F.: The structure of autobiographical memory and the event history calendar: potential improvements in the quality of retrospective reports in surveys. Memory 6, 383-406 (1998). https://doi. org/10.1080/741942610

Bhat, C.R.: A hazard-based duration model of shopping activity with nonparametric baseline specification and nonparametric control for unobserved heterogeneity. Transp. Res. Part B Methodol. 30, 189-207 (1996)

Bhat, C.R., Pulugurta, V.: A comparison of two alternative behavioral choice. Transp. Res. Part B Methodol. 32, 61-75 (1998)

Bhat, V., Oates, T., Shanbhag, V., Nicholas, C.: Finding aliases on the web using latent semantic analysis. Data Knowl. Eng. 49, 129-143 (2004)

Cao, X., Næss, P., Wolday, F.: Examining the effects of the built environment on auto ownership in two Norwegian urban regions. Transp. Res. Part D Transp. Environ. 67, 464-474 (2019). https://doi. org/10.1016/j.trd.2018.12.020 
Chen, C., Niemeier, D.: A mass point vehicle scrappage model. Transp. Res. Part B Methodol. 39, 401-415 (2005). https://doi.org/10.1016/j.trb.2004.06.003

Clark, S.D.: Estimating local car ownership models. J. Transp. Geogr. 15, 184-197 (2007). https://doi. org/10.1016/j.jtrangeo.2006.02.014

Clark, B., Chatterjee, K., Melia, S.: Changes in level of household car ownership: the role of life events and spatial context. Transportation (Amst). 43, 565-599 (2016). https://doi.org/10.1007/s1111 6-015-9589-y

de Jong, G., Fox, J., Daly, A., Pieters, M., Smit, R.: Comparison of car ownership models. Transp. Rev. 24, 379-408 (2004). https://doi.org/10.1080/0144164032000138733

Ding, C., Wang, Y., Tang, T., Mishra, S., Liu, C.: Joint analysis of the spatial impacts of built environment on car ownership and travel mode choice. Transp. Res. Part D Transp. Environ. 60, 28-40 (2018). https ://doi.org/10.1016/j.trd.2016.08.004

Guerra, E.: The geography of car ownership in Mexico City: a joint model of households' residential location and car ownership decisions. J. Transp. Geogr. 43, 171-180 (2015). https://doi.org/10.1016/j.jtran geo.2015.01.014

Guo, Z.: Does residential parking supply affect household car ownership? The case of New York City. J. Transp. Geogr. 26, 18-28 (2013). https://doi.org/10.1016/j.jtrangeo.2012.08.006

Haller, B., Schmidt, G., Ulm, K.: Applying competing risks regression models: an overview. Lifetime Data Anal. 19, 33-58 (2012). https://doi.org/10.1007/s10985-012-9230-8

Han, A., Hausman, J.A.: Flexible parametric estimation of duration and competing risk models. J. Appl. Econom. 5, 1-28 (1990)

Hasan, S., Mesa-Arango, R., Ukkusuri, S.: A random-parameter hazard-based model to understand household evacuation timing behavior. Transp. Res. Part C Emerg. Technol. 27, 108-116 (2013)

Heckman, J., Heckman, J., Singer, B., Singer, B.: The identifiability of the proportional hazard model. Rev. Econ. Stud. 51, 231-241 (1984). https://doi.org/10.2307/2297689

Hollingworth, B., Miller, E.: Retrospective interviewing and its application in study of residential mobility. Transp. Res. Rec. J. Transp. Res. Board 1551, 74-81 (1996). https://doi.org/10.3141/1551-10

Huang, X., Cao, X., Yin, J., Cao, X.: Effects of metro transit on the ownership of mobility instruments in Xi'an, China. Transp. Res. Part D Transp. Environ. 52, 495-505 (2017). https://doi.org/10.1016/j. trd.2016.09.014

Jong, D.E.: A disaggregate model system of vehicle holding duration, type choice and use. Transp. Res. Part B Methodol. 30, 263-276 (1996)

Kim, S., Yang, D., Rasouli, S., Timmermans, H.J.P.: Heterogeneous hazard model of PEV users charging intervals: analysis of four year charging transactions data. Transp. Res. Part C Emerg. Technol. 82, 248-260 (2017)

Koller, M.T., Raatz, H., Steyerberg, W., Wolbers, M.: Diagnosis eimeria caviae infection. Stat. Med. 31, 1089-1097 (2012). https://doi.org/10.1002/sim.4384

Lee, B., Timmermans, H.J.P.: A latent class accelerated hazard model of activity episode durations. Transp. Res. Part B Methodol. 41, 426-447 (2007)

Leszczyc, P.T.L.P., Timmermans, H.J.P.: Unconditional and conditional competing risk models of activity duration and activity sequencing decisions: an empirical comparison. J. Geogr. Syst. 4, 157-170 (2002)

Mohammadian, A., Rashidi, T.: Modeling household vehicle transaction behavior, competing risk duration approach. Transp. Res. Rec. J. Transp. Res. Board 2014, 9-16 (2007)

Oakil, A.T., Ettema, D., Arentze, T., Timmermans, H.J.P.: Changing household car ownership level and life cycle events: an action in anticipation or an action on occurrence. Transportation (Amst). 41, 889-904 (2014)

Oakil, A.T., Manting, D., Nijland, H.: Determinants of car ownership among young households in the Netherlands: the role of urbanisation and demographic and economic characteristics. J. Transp. Geogr. 51, 229-235 (2016)

Oakil, A.T., Manting, D., Nijland, H.: The role of individual characteristics in car ownership shortly after relationship dissolution. Transportation (Amst). 45, 1871-1882 (2018). https://doi.org/10.1007/s1111 6-018-9867-6

Paleti, R., Mishra, S., Haque, K., Sarker, A.A., Golias, M.M.: Latent class analysis of residential and work location choices. Transp. Res. Rec. J. Transp. Res. Board. 6430, 1-16 (2017)

Potoglou, D., Kanaroglou, P.S.: Modelling car ownership in urban areas: a case study of Hamilton. Canada. J. Transp. Geogr. 16, 42-54 (2008)

Putter, H., Fiocco, M., Geskus, R.B.: Tutorial in biostatistics: Competing risks and multi-state models. Stat. Med. 26, 2389-2430 (2007) 
Rashidi, T.H., Mohammadian, A.: Application of a Gumbel multivariate distribution in a competing duration hazard-based vehicle transaction decision (2011)

Rashidi, T.H., Mohammadian, A., Koppelman, F.S.: Modeling interdependencies between vehicle transaction, residential relocation and job change. Transportation (Amst). 38, 909-932 (2011). https://doi. org/10.1007/s11116-011-9359-4

Rasouli, S., Timmermans, H.J.P.: Activity-based models of travel demand: promises, progress and prospects. Int. J. Urban Sci. 18, 31-60 (2014)

Sharmeen, F., Arentze, T., Timmermans, H.: An analysis of the dynamics of activity and travel needs in response to social network evolution and life-cycle events: a structural equation model. Transp. Res. Part A Policy Pract. 59, 159-171 (2014). https://doi.org/10.1016/j.tra.2013.11.006

Van Den Berg, P., Arentze, T., Timmermans, H.J.P.: A latent class accelerated hazard model of social activity duration. Transp. Res. Part A 46, 12-21 (2012)

Verhoeven, M., Arentze, T., Timmermans, H., van der Waerden, P.: Modeling the impact of key events on long-term transport mode choice decisions: decision network approach using event history data. Transp. Res. Rec. J. Transp. Res. Board. 1926, 106-114 (2005)

Wang, B., Rasouli, S., Timmermans, H., Shao, C.: Relationships between consecutive long-term and midterm mobility decisions over the life course: a Bayesian network approach. Transp. Res. Rec. (2018). https://doi.org/10.1177/0361198118777604

Wolbers, M., Blanche, P., Koller, M.T., Witteman, J.C.M., Gerds, T.A.: Concordance for prognostic models with competing risks. Biostatistics 15, 526-539 (2014a). https://doi.org/10.1093/biostatistics/kxt059

Wolbers, M., Koller, M.T., Stel, V.S., Schaer, B., Jager, K.J., Leffondre, K., Heinze, G.: Competing risks analyses: objectives and approaches. Eur. Heart J. 35, 2936-2941 (2014b)

Yamamoto, T.: The impact of life-course events on vehicle ownership dynamics-the Cases of France and Japan. Int. Assoc. Traffic Saf. Sci. 32, 34-43 (2008)

Yamamoto, T., Kitamura, R.: An analysis of household vehicle holding durations considering intended holding durations. Transp. Res. Part A Policy Pract. 34, 339-351 (2000)

Yamamoto, T., Madre, J.L., Kitamura, R.: An analysis of the effects of French vehicle inspection program and grant for scrappage on household vehicle transaction. Transp. Res. Part B Methodol. 38, 905-926 (2004)

Publisher's Note Springer Nature remains neutral with regard to jurisdictional claims in published maps and institutional affiliations.

Gaofeng Gu is a PhD candidate in Urban Planning and Transportation Group at the Eindhoven University of Technology. His research focuses on econometric modeling and their applications on travel behavior analysis, household long-term decision, and car type choice. He has also investigated the innovative methods of collecting the integrated energy decision data and analyzing the data using choice methods.

Tao Feng is Assistant Professor of the Urban Planning Group of the Eindhoven University of Technology. His areas of interest include travel demand forecasting, travel behavior analysis, big data, housing and mobility decision and land use and transportation. He is the associated editor of journal Asia Transport Studies.

Dr. Dujuan Yang is an assistant professor of the Information Systems in the Built Environment (ISBE) group. Her main areas of expertise are travel behavior modeling, urban infrastructure management, energy neutral city development, and decision support system. She has published over 20 Journal papers in Urban planning, Transportation Research Part B, C, D, Informatics, Transport Policy and Journal of Transport Geography, and several book chapters.

Harry Timmermans is Professor of the Urban Planning Group of the Eindhoven University of Technology. $\mathrm{He}$ has research interests in modeling decision-making processes and decision support systems in a variety of application domains, including transportation. He is editor of the Journal of Retailing and Consumer Services, and serves on the board of several other journals in transportation, geography, urban planning, marketing, artifcial intelligence and other disciplines. He is member of the Board of the International Association of Travel Behavior Research (IATBR), and of several scientifc committees of the Transportation Research Board. 